\title{
LINGUISTICS
}

\section{CREATING A NEGATIVE IMAGE OF A SOCIAL GROUP IN INTOLERANT DISCOURSE: LINGUOPRAGMATIC ASPECT}

\author{
Ekaterina Vasilenko \\ PhD in Philology, Associate Professor \\ Mogilev State A. Kulesov University \\ (Mogilev, Republic of Belarus) \\ e-mail: e.n.vasilenko@gmail.com
}

\begin{abstract}
The article is devoted to the study of the communicative and pragmatic organization of intolerant discourse as a sphere of manifestation of the speaker's negative attitude to certain social groups. The article discusses the communicative strategy of discrediting of they-group within the framework of intolerant online communication. Examples of tactics aimed at creating a negative image of a social group are given based on Belarusian Internet users' comments to news articles about women, LGBT people and foreigners. It is established that tactics aimed at creating a negative image of a social group include those of accusation, attributing hostile intentions, prediction and polarization. The tactics are presented in a form of models.
\end{abstract}

Key words: intolerant discourse, hostility, hate speech, social group, online comment, strategy of discrediting.

\section{СОЗДАНИЕ НЕГАТИВНОГО ОБРАЗА СОЦИАЛЬНОЙ ГРУППЫ В ИНТОЛЕРАНТНОМ ДИСКУРСЕ: ЛИНГВОПРАГМАТИЧЕСКИЙ АСПЕКТ}

\author{
Екатерина Василенко \\ кандидат филологических наук, доцент \\ Могилевский государственный университет имени А. А. Кулешова \\ (Могилев, Республика Беларусь) \\ e-mail: e.n.vasilenko@gmail.com
}

\begin{abstract}
Аннотация. Статья посвящена изучению коммуникативно-прагматической организации интолерантного дискурса как сферы манифестации враждебного отношения говорящего к определенным социальным группам. Автором рассматривается коммуникативная стратегия дискредитации они-группы в рамках интолерантной онлайн-коммуникации. В качестве примеров актуализации тактик, направленных на создание негативного образа социальной группы, приводятся комментарии белорусских интернет-пользователей к новостным статьям о женщинах, ЛГБТ-людях и иностранцах. Установлено, что к тактикам, направленным на создание негативного образа социальной группы, относятся тактики обвинения, приписывания враждебных намерений, прогнозирования и поляризации. Перечисленные тактики представлены в статье в виде моделей.
\end{abstract}


Ключевые слова: интолерантный дискурс, враждебность, «язык вражды», социальная группа, интернет-комментарий, стратегия дискредитации.

\section{ВВЕДЕНИЕ}

В мировой гуманитаристике все больше публикаций посвящается изучению интолерантной коммуникации вообще и «языка вражды» (hate speech) как формы манифестации интолерантного отношения к отдельным социальным группам в частности (Paz et al., 2020), что связано с возрастающим количеством разного рода проявлений межгрупповых конфликтов ценностей ввиду мультикультурализма современного общества (Vasilenko, 2021).

Одной из ключевых особенностей интолерантного дискурса, как и других типов дискурса власти, выступает его ярко выраженная прагматическая направленность (например, о прагматическом аспекте политического дискурса см. Vasilenko, 2018). Выбор тех или иных языковых средств, речевых приемов и тактик в рамках интолерантного дискурса во многом носит преднамеренный характер и может рассказать не только о коммуникативной интенции говорящего, но и о его внутренних когнитивных установках (см., например, классическую работу Т. А. ван Дейка о вербализации расизма - Dijk, 1987).

В этом связи полагаем, что одной из важнейших задач современной лингвистики является разработка отдельной таксономии коммуникативных стратегий, вербализующих враждебность по отношению к определенным социальным группам.

\section{МЕТОДОЛОГИЯ ИССЛЕДОВАНИЯ}

Принимая во внимание, что особый интерес лингвистов вызывает анализ вербализации враждебности в онлайн-коммуникации, позволяющей адресанту сообщения оставаться анонимным (Assimakopoulos et al., 2017; Brown, 2018), фактическим материалом исследования послужили комментарии интернет-пользователей к новостным статьям о трех уязвимых социальных группах женщинах, ЛГБТ-людях и иностранцах. Все комментарии отобраны из белорусского сегмента Всемирной сети (подробнее об отборе материала см. Vasilenko, 2020a; Vasilenko, 2020b).

В ходе исследования было установлено, что в рамках интолерантного дискурса актуализируются коммуникативные стратегии дискредитации, положительной самопрезентации, манипулирования, убеждения и речевой провокации. Учитывая, что коммуникативная стратегия убеждения попадает, в первую очередь, в фокус внимания теории аргументации, а стратегия речевой провокации используется говорящим для непосредственного влияния на реакцию собеседника, а не на его картину мира, полагаем, что основной интерес для изучения вербализации враждебности в онлайн-коммуникации представляют стратегии дискредитации, положительной самопрезентации и манипуляции.

Объектом нашего исследования выступает коммуникативнвя стратегия дискредитации, представляющая собой негативную презентацию или принижение они-группы представителями мыгруппы (в психологии используются термины «аутгруппа» и «ингруппа» соответственно - см, например, Whitley and Kite, 2010).

В ходе анализа фактического материала было выявлено, что все речевые тактики, направленные на реализацию стратегии дискредитации, можно условно разделить на три группы: 1) тактики, непосредственно направленные на принижение социальной группы; 2) тактики, 
направленные на создание негативного образа социальной группы; и 3) тактики, направленные на продвижение интолерантности. Интерес для нашего исследования представляют тактики, относящиеся ко второй группе.

\section{РЕЗУЛЬТАТЫ И ДИСКУССИЯ}

К тактикам, направленным на создание негативного образа социальной группы, относятся тактики обвинения, приписывания враждебных намерений, прогнозирования и поляризации (в основе выделения тактик лежит подход, предложенный в (Romanova et. al., 2017). Поясним, что в представленных моделях под $\mathrm{X}$ всегда понимается уязвимая социальная группа, под $\mathrm{Y}$ доминирующая социальная группа. Значение других переменных варьируется и уточняется в каждом конкретном случае. Орфография и пунктуация авторов комментариев незначительно откорректированы для лучшего восприятия; в квадратных скобках после примеров указан номер социальной группы, которой адресован комментарий: Г-1 - женщины, Г-2 - ЛГБТ-люди, Г-3 иностранцы.

Тактика обвинения заключается «в приписывании кому-либо вины, представлении ситуации и оппонента в негативном свете» (Akopova, 2013: 404). Несмотря на то, что обвинение, в отличие от оскорбления, требует обоснований и доказательств (Romanova et. al., 2017: 164), в интолерантном дискурсе обвинение может быть неаргументированным и голословным.

Обвинение в интолерантном онлайн-дискурсе может быть эксплицированным, т. е. выраженным Моделью 1: Х виноваты в проблеме A (вариант: Проблема A-из-за X), например: Если он толстый, и сынишка в папу, то виновата жена. Кормит их неполезной пищей, а сама, видать, на диетах сидит [Г-1].

Обвинение может быть имплицированным, не маркированным особым набором языковых или коммуникативных средств. При этом в заданных дискурсивных условиях отчетливо прослеживается оппозиция $\mathrm{Mbl}$ - они, так как эта тактика зачастую используется для актуализации темы «Они угрожают нашему традиционному укладу» (о когнитивно-тематической организации интолерантного дискурса см. Vasilenko, 2020a; Vasilenko, 2020b). Например, автор следующего комментария видит в трудовых мигрантах причину нехватки высокооплачиваемых рабочих мест в Беларуси и доказывает свою позицию ссылкой на личный опыт: обидно то, что для китайцев и украинцев находятся места, притом вполне себе высокооплачиваемые (знаю на своем опыте), зато своим в родной стране места нет... даже за 260 не говоря о 500 [Г-3].

В следующем примере ЛГБТ-людей обвиняют в вероятных демографических проблемах. Автор комментария прибегает к использованию риторических вопросов для подкрепления своего мнения: $B$ целом считаю ЛГБТ не может объявляться государством, как норма. Кто будет решать демографическую проблему? Рано или поздно, это поколение ЛГБТ или следующее, приведут к остановке прироста населения. И кто будет платить пенсии старикам? Кто будет развивать страну под следующие поколения? Культивирование ЛГБТ - есть продвижение стерилизация cmpaны [Г-2]. Этот комментарий наглядно демонстрирует связь тактики обвинения с тактиками, направленными на конструирование возможных неблагоприятных ситуаций, связанных с онигруппой, к которым относятся тактики приписывания враждебных намерений и прогнозирования.

Тактика приписывания враждебных намерений заключается в конструировании негативного образа они-группы посредством атрибуции ее представителям злого умысла и разрушительных для устоявшегося порядка планов (Модель 2: $X$ сделают $Z$, где Z - нежелательные для мы-группы действия): Вы можете фантазировать и рассуждать по всякому. Встречаться, 
обниматься, но результат будет всегда один - отношение как к людям 2-го сорта. И пренебрежение. Я не знаю в каком Вы мире живёте, что если есть малейшая возможность - они ограбят, подставят или убьют. Для меня это уже аксиома. Давно [Г-3Error! Reference source not found.]; Скоро женщины обвинят нас в том, что мы мужчины [Г-1].

Тактика прогнозирования также позволяет говорящему проецировать свое негативное отношение к социальной группе на будущее. Основным отличием от предыдущей тактики выступает акцентирование негативных последствий изменения традиционного жизненного уклада для мыгруппы без указания на наличие умысла у представителей они-группы (Модель 3: Продвижение прав

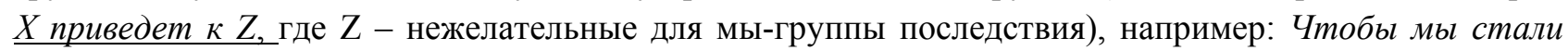
вымирать как толерантные немиы или франиузы? А кто вам в старости воды подаст? [Г-2]; зачем ему готовить, о как отдельная личность питается и зарабатывает как хочет, а с вами только секс, какие дети, с вами нашему обществу в будущчем обеспечена деградация женского населения и увеличение численности “аленей” [Г-1].

Таким образом, основным маркером тактик приписывания враждебных намерений и прогнозирования (очевидно, помимо соответствующей лексики) выступает форма глагола будущего времени изъявительного наклонения, позволяющая говорящему представить возможную неблагоприятную ситуацию как реальную (вместо могут сделать - сделают). Обе тактики представляют собой косвенное обвинение и, следовательно, раскрывают тему «Они угрожают нашему традиционному укладу», т. е. актуализируют когнитивную оппозицию $м ы$ - они.

Из всех тактик, реализуемых в интолерантном дискурсе, противопоставление «своего» и «чужого», выраженное Моделью 4: Они, X, плохие; мы, Y, хорошие, наиболее очевидным образом отражает тактика поляризации, или тактика дискредитации «чужого» и возвышения «своего» (Romanova et. al., 2017: 174). Оппозиция мы - они является основой интолерантного дискурса, поэтому важнейшим способом вербализации тактики поляризации выступает прагматическое противопоставление местоимений первого и третьего лица. При этом исследовательский интерес вызывают не только личные, но и притяжательные местоимения, входящие в исходный смысл чей, который «порожден и во многом сдублирован» исходным смыслом кто, включающим в себя личные местоимения (Shvedova, 1998: 41).

Это противопоставление служит одним из важнейших средств моделирования в сознании слушающего особой дискурс-картины мира: в то время как первое лицо множественного числа, как правило, отражает принадлежность человека к «своей» группе, понятие они склонно к негативной коннотации, так как аккумулирует в себе значение далекого и неизвестного: «В сферу множественного 3-го лица втягиваются такие межличностные отношения, как незнание, дистанцирование, недоверие, неприязнь, вражда и т. п.» (Norman, 2014: 194]. В скобках отметим, что прагматический потенциал местоимений обусловлен простотой их формы и многослойностью их значения (Bloomfield, 1973: 247-248; Yule, 1996: 10] и проявляется при реализации и других тактик, например кооперации и дистанцирования (Vasilenko, 2018).

Наиболее ярко тактика поляризации мы-группы и они-группы демонстрируется на примерах комментариев, раскрывающих темы «Они хуже, чем мы» и «Они угрожают нашем традиционному укладу», например: Да, да, да, в Швейцарии живут не богатые а очень богатые люди. Но посмотрев на их вилль, и сравнив с нашими кирпичными коттеджами - наши вынгрывают. Мы беднее, но со вкусом у нас все в порядке. Свои сбережения швейцарцуы могут завещуать своим котам и собакам, а наши - своим детям. И с любовью у нас все в порядке. И не надо нам, славянам, подкидывать ваши сравнения. Мы - не они, а они - не мы [Г-3]; Это люди с проблемами! Мы их и так терпим. Так они теперь и публично решили доказывать непонятно что? [Г-2Error! Reference source not found.]. 
В некоторых случаях авторы комментариев используют прямое обращение, и тогда оппозиция выглядит как $\mathrm{Mbl}-\mathbf{c в о u , ~ в b l - ч у ж и е ~ ( з д е с ь , ~ к а к ~ и ~ п р и ~ п р о т и в о п о с т а в л е н и и ~ п е р в о г о ~ и ~ т р е т ь е г о ~ л и ц а ~}$ одно из местоимений может опускаться), например: вам никто не дал право навязывать свой образ жизни НОРМАЛЬНЫМ ЛЮДЯМ [Г-2]; Чего в нашу страну ехать? Или в сказку хотите? [Г-3]; Нет уж, раз вы все такие равноправные и хотите одинаковых прав, свобод и прочего наравне $c$ мужиками - тогда перестаньте при каждом удобном случае давить на то, что вы “слабый пол”. А то ходить в штанах, голосовать на выборах, зарабатывать наравне и т.д. - это мы хотим, а нести ответственность, делить обязанности наравне с мужиками - тут сразу “ну я же девочка, ты разве не джентльмен?”. Тьфу. Вот так постепенно и превращаешься в женоненавистника, незаметно для себя самого [Г-1]. В последнем комментарии примечательно употребление эксклюзивного $\mathrm{mbl}$, являющегося разновидностью так называемого «докторского» $\mathrm{Mbl}$. Как правило, такое $\mathrm{Mbl}$ свидетельствует о стремлении к интимизации общения, к ощущению сочувствия (Norman, 2017: 54), однако в данном контексте оно очевидным образом приобретает неодобрительный оттенок и демонстрирует некоторое пренебрежение и даже высокомерие по отношению к адресату.

Отметим также использование местоименных наречий для размежевания «своего» и «чужого» в случае с Группой 3. Здесь отсылает к локусу «своего» мира, там - «чужого», понимаемого как 'все, что не здесь': предупреждение кавказской мафии? я считаю это четко и правильно. Здесь им не там [Г-3]; <..> здесь mы “свой”, там - никто [Г-3]. Автор последнего комментария подчеркивает принадлежность к «своему» миру посредством соответствующего поссесива, раскрывающего а рассматриваемом контексте значение 'хороший'. Однако оценочная семантика местоимения «свой» может варьироваться от «хороший» до «плохой». Противоположный полюс его оценочного значения можно продемонстрировать следующими примерами: Если бы это было ПРИРОДНОЙ нормой, то они могли бы размножаться без участия противоположного пола. Так что прекратите пропогандировать свое голубиное братство [Г-2]; Спасибо, не надо, меркель со своим женским “особым взглядом” уже натворила делов, забила на благосостояние самих немиев и спускает бабло на нелегалов [Г-1].

\section{ЗАКЛЮЧЕНИЕ}

Таким образом, в рамках интолерантного дискурса негативный образ социальной группы создается при помощи тактик обвинения, приписывания враждебных намерений, прогнозирования и поляризации. Обвинение в рамках интолерантного дискурса заключается в приписывании онигруппы вины и может быть неаргументированным и бездоказательным. Обвинение строится по модели $X$ виноваты в проблеме $A$ и может быть выражено как эксплицитно, так и имплицитно. Эта тактика используется интернет-пользователями для актуализации темы «Они угрожают нашему традиционному укладу» и пересекается с тактиками приписывания враждебных намерений $(X$ cделают Z) и прогнозирования (Продвижение прав $X$ приведет $\kappa Z$ ), помогающими комментаторам моделировать гипотетические неблагоприятные ситуации, связанные с они-группой. Конструирование возможного варианта развития событий осуществляется в рамках данных тактик при помощи глаголов будущего времени изъявительного наклонения. Основанием для разграничения тактики приписывания враждебных намерений и тактики прогнозирования служит наличие или отсутствие указания на наличие злого умысла у представителей они-группы. Базовую оппозицию интолерантного дискурса свое - чужое отражает тактика поляризации, выраженная моделью Они, $X$, плохие; $\mathrm{Mbl,} Y$, хорошие. Маркером этой тактики выступает противопоставление личных и притяжательных местоимений первого и третьего (или - в случае прямого обращения - первого и второго) лица множественного числа. В рамках тактики поляризации свой прагматический потенциал раскрывает также поссесив свой. Для размежевания «своего» и «чужого» может использоваться оппозиция местоименных наречий здесь и там. 


\section{LIST OF REFERENCES}

Akopova, D. R. (2013). Strategii i taktiki politicheskogo diskursa [Strategies and tactics of political discourse]. Vestnik Nizhegorodskogo universiteta imeni N. I. Lobachevskogo. Serija Filologija, 6 (1), 403-409.

Assimakopoulos, S., Baider, F. H., \& Millar, S. (2017). Online hate speech in the European Union: a discourse-analytic perspective. Cham: Springer.

Bloomfield, L. (1973). Language. London: George Allen and Unwin Ltd.

Brown, A. (2018). What is so special about online (as compared to offline) hate speech? Ethnicities, 18 (3), 297-326.

Dijk, T. A. van (1987). Communicating racism: Ethnic prejudice in thought and talk. Newbury Park, Beverly Hills, London, New Delhi: Sage Publications.

Norman, B. Ju. (2017). Pragmaticheskij potencial russkoj leksiki i grammatiki [Pragmatic potential of Russian lexis and grammar]. Ekaterinburg; Moskva: Kabinetnyj uchenyj.

Paz, M. A., Montero-Díaz, J., \& Moreno-Delgado, A. (2020). Hate Speech: A Systematized Review. SAGE Open, 10, 1-12. https://J.s.sagepub.com/doi/pdf/10.1177/2158244020973022.

Romanova, T. V., Malafeev, A. Yu., Morozova, N. N., \& Klimova (Fokina), M. A. (2017). Tolerantnost' kak kul'turnaya, politicheskaya, lingvisticheskaya problema [Tolerance as a cultural, political and linguistic problem]. Nizhnii Novgorod: DEKOM.

Shvedova, N. Ju. (1998). Mestoimenie i smysl. Klass russkih mestoimenij i otkryvaemye imi smyslovye prostranstva [Pronoun and meaning. The class of Russian pronouns and semantic spaces the open]. Moskva: Azbukovnik.

Vasilenko, E. (2020a). Ksenofobskaya ritorika: tematicheskaya organizatsiya intolerantnogo diskursa [Xenophobic rhetoric: Thematic organization of intolerant discourse]. Filologichni studii. Naukovii visnik Krivoriz'kogo derzhavnogo pedagogichnogo universitetu, 21, 123-132.

Vasilenko, E. (2020b). Sexist hate speech: Topical organization of intolerant discourse. Językoznawstwo, 14, 47-60. DOI: $10.25312 / 2391-5137.14 / 2020 \_03 e v$

Vasilenko, E. N. (2018). Jazykovye sredstva ubezhdenija v politicheskom diskurse [Language means of persuasion in political discourse]. Mogilev: MGU imeni A. A. Kuleshova.

Vasilenko, E. N. (2021). «Jazyk vrazhdy» kak forma projavlenija konfliktov, osnovannyh na stereotipah [Hate speech as a form of manifestation of conflicts based on stereotypes]. Trudy BGTU. Serija 4, Print- i mediatehnologii, 2 (249), 90-97.

Whitley, B. E. Jr., \& Kite, M. E. (2010). The psychology of prejudice and discrimination. (2nd ed.). Wadsworth: Cengage Learning.

Yule, G. (1996). Pragmatics. London: Oxford Univ. Press. 


\title{
For citation:
}

Vasilenko, E. (2021). Creating a negative image of a social group in intolerant discourse: linguopragmatic aspect // International Scientific-Pedagogical Organization of Philologists "WEST - EAST" (ISPOP). Scientific Journal "WEST

- EAST". Vol. 6, N1 (October, 2021), pp.85-92. doi

\section{Для цитирования:}

Василенко, Е. (2021). Создание негативного образа социальной группы в интолерантном дискурсе: лингвопрагматический аспект // International Scientific-Pedagogical Organization of Philologists "WEST - EAST" (ISPOP). Scientific Journal "WEST - EAST". Vol. 6, N1 (October, 2021), C. 85-92. doi

\section{Information about the author:}

Ekaterina Vasilenko - PhD in Philology, Associate Professor, Associate Professor of the Department of Theoretical and Applied Linguistics, Mogilev State A. Kuleshov University, Mogilev, Republic of Belarus.

e-mail: e.n.vasilenko@gmail.com

\section{Информация об авторе:}

Екатерина Василенко - кандидат филологических наук, доцент, доцент кафедры теоретической и прикладной лингвистики Могилевского государственного университета имени А. А. Кулешова, Могилев, Республика Беларусь.

эл. почта: e.n.vasilenko@gmail.com

Manuscript received: 08/14/2021

Accepted for publication: $09 / 14 / 2021$

Рукопись получена: 08/14/2021

Принята к печати: 09/14/2021

\author{
International Scientific-Pedagogical Organization of Philologists "West-East" ISPOP \\ SCIENTIFIC JOURNAL “ WEST-EAST" \\ ISSN (print) - 2587-5434 ISSN (online) - 2587-552
}

